\title{
PENERAPAN MODEL PEMBELAJARAN KOOPERATIF TIPE STUDENT TEAMS ACHIEVEMENT DIVISION (STAD) UNTUK MENINGKATKAN KEMAMPUAN PEMECAHAN MASALAH DAN PENALARAN MATEMATIS
}

\author{
Chyntia Pasalbessy ${ }^{*}$, Wilmintjie Mataheru², Carolina S. Ayal ${ }^{3}$ \\ 1,2,3Prodi Magister Pendidikan Matematika, Pascasarjana, Universitas Pattimura \\ Jalan Dr. Tamaela, Kampus PGSD, Ambon, Indonesia \\ e-mail: ${ }^{1}$ thia011090@gmail.com;
}

corresponding author*

\begin{abstract}
Abstrak
Kemampuan pemecahan masalah matematis penting bagi siswa untuk menyelesaikan masalah dalam pembelajaran matematika. Tujuan penelitian ini adalah menganalisis perbedaan peningkatan kemampuan pemecahan masalah matematis antara siswa dengan menggunakan model pembelajaran kooperatif tipe STAD dan pengajaran langsung. Jenis penelitian ini adalah penelitian eksperimen dengan pendekatan kuantitatif. Subjek dalam penelitian ini adalah siswa kelas VIII SMP Kristen Kalam Kudus Ambon pada semester 1 tahun pelajaran 2019/2020, yang terdiri dari dua kelas. Metode pengumpulan data melalui tes kemampuan awal matematis dan tes kemampuan pemecahan masalah. Hasil penelitian ini menunjukkan terdapat perbedaan peningkatan kemampuan pemecahan masalah matematis antara siswa yang memperoleh pembelajaran dengan menggunakan model kooperatif tipe STAD dan pengajaran langsung
\end{abstract}

Kata Kunci: pemecahan masalah, penalaran matematis, pembelajaran kooperatif tipe stad

\section{APPLICATION OF COOPERATIVE LEARNING MODEL STUDENTS TEAMS ACHIEVEMENT DIVISION (STAD) TYPE TO IMPROVE PROBLEM SOLVING ABILITY AND MATHEMATICAL REASONING ABILITY}

\begin{abstract}
The mathematical problem solving ability is important for students to solve problems in mathematics learning. The purpose of this study was analyzed the difference in improvement of mathematical problem solving ability between students who use STAD type of cooperative learning model and direct teaching. This type research is experimental research with a quantitative appoarch. The subjects in this study were eighth-grade students of the SMP Kalam Kudus Ambon in the first semester of the 2019/2020 academic calendar, which consisted of two classes. Methods of data collection through an Initial Ability Mathematics test and a mathematical problem solving ability test. The result showed that there was a difference increase in ability of problem solving between students who obtain learning by using the STAD type cooperative learning models and direct teaching
\end{abstract}

Keywords: problem solving, mathematical reasoning, stad type cooperative model

\section{Pendahuluan}

Salah satu materi yang sangat diperlukan dalam perkembangan ilmu pengetahuan dan teknologi adalah matematika. Bagi semua siswa dari tingkat sekolah dasar sampai tingkat lanjutan atas, mata pelajaran matematika sangat penting untuk diberikan supaya dapat bertahan hidup pada keadaan yang selalu berubah dan kompetitif. Karena melalui pelajaran matematika siswa dapat memiliki kemampuan berpikir logis, kritis, kreatif, analitis, dan sistematis, serta kemampuan bekerjasama, kompetensi memperoleh, mengelola dan memanfaatkan informasi.

Hal ini sejalan dengan Permendiknas Nomor 22 Tahun 2006 tentang Standar Isi merumuskan tujuan umum pembelajaran matematika, yaitu agar siswa memiliki kemampuan: 1) memahami konsep matematika, menjelaskan keterkaitan antar konsep 
atau algoritma secara luwes, akurat, efisien, dan tepat dalam pemecahan masalah, 2) Menggunakan penalaran pada pola dan sifat, melakukan manipulasi matematika dalam membuat generalisasi, menyusun bukti, atau menjelaskan gagasan dan pernyataan matematika, 3) memecahkan masalah yang meliputi kemampuan memahami masalah, merancang model matematika, menyelesaikan model, dan menafsirkan solusi yang diperoleh, 4) mengkomunikasikan gagasan dengan simbol, tabel, diagram, atau media lain untuk memperjelas keadaan atau masalah, 5) memiliki sikap menghargai kegunaan matematika dalam kehidupan, yaitu rasa ingin tahu, perhatian, dan minat dalam mempelajari matematika, serta sikap ulet dan percaya diri dalam pemecahan masalah.

Agar tercapainya tujuan umum pembelajaran matematika di sekolah, maka selain membantu meningkatkan prestasi akademik siswa, perlu meningkatkan kemampuan matematis siswa. Selain itu, dalam pembelajaran matematika siswa juga harus memiliki kemampuan awal matematis (KAM) yang baik agar dapat terlibat aktif dalam menghadapi dan menyelesaikan masalah-masalah matematika yang menantang. Dalam pembelajaran matematika di sekolah, kemampuan matematis yang dianggap penting dan perlu ditingkatkan adalah kemampuan pemecahan masalah dan penalaran matematis. Menurut Hudojo (Octizasari, dkk, 2018: 2) menyatakan dalam menyelesaikan masalah, siswa perlu memahami proses penyelesaian masalah dan terampil dalam memilih dan mengidentifikasi kondisi dan konsep yang relevan, mencari generalisasi, merumuskan rencana penyelesaian dan mengorganisasikan keterampilan yang telah dimiliki sebelumnya. Untuk itu siswa diharapkan memiliki kemampuan pemecahan masalah dan daya nalar yang baik terutama ketika menyelesaikan masalah dalam pembelajaran matematika.

Krulik dan Rudnik (Hendriana, dkk. 2017: 44) menjelaskan bahwa kemampuan pemecahan masalah adalah kemampuan penyelesaian masalah pada situasi yang belum dikenal sebelumnya dengan menggunakan pengetahuan, ketrampilan, serta pemahaman yang telah diperoleh. Kemampuan pemecahan masalah adalah kemampuan melakukan beberapa kegiatan seperti pengamatan, pemahaman, percobaan, pendugaan, penemuan dan peninjauan kembali untuk menemukan metode atau pendekatan penyelesaian suatu masalah. Keraf (Hendriana, dkk. 2017: 26) menjelaskan penalaran adalah usaha menghubungkan fakta-fakta yang diketahui melalui proses berpikir untuk memperoleh suatu kesimpulan. Dalam matematika, penalaran matematis adalah proses berpikir matematik dalam memperoleh kesimpulan matematis berdasarkan fakta atau data, konsep, dan metode yang tersedia atau yang relevan.

Siswa mengalami kesulitan dalam pemecahan dan penalaran matematis, untuk mengatasi kesulitan yang dihadapi siswa tersebut dan untuk meningkatkan kemampuan pemecahan dan penalaran matematis, maka dalam pembelajaran matematika hendaknya dikembangkan model pembelajaran yang tidak hanya berpusat pada guru saja tetapi pembelajaran yang melibatkan keaktifan siswa. Selain itu juga perlu diterapkan model pembelajaran yang dapat membantu mengembangkan kemampuan matematis siswa serta pembelajaran yang menyenangkan, efektif, dan bermakna.

Menurut Vygotsky (Muhsetyo, dkk, 2007: 11), melalui kegiatan yang beranekaragam, siswa dapat memperoleh pengetahuan dan membangun sendiri pengetahuannya. Kegiatan itu dapat berupa diskusi kelompok kecil, diskusi kelas, mengerjakan tugas kelompok, tugas menulis, tugas bersama membuat laporan kegiatan pengamatan atau kajian matematika, dan tugas menyampaikan penjelasan atau mengkomunikasikan pendapat atau presentasi tentang sesuatu yang terkait dengan matematika. Kegiatan siswa yang beragam ini dapat membangun pengetahuannya sendiri melalui membaca, pencatatan, pengerjaan dan presentasi.

Model pembelajaran kooperatif merupakan pembelajaran yang menyenangkan dan terpusat pada siswa. Terdapat tiga struktur dalam model pembelajaran kooperatif, yaitu struktur tugas, struktur tujuan dan struktur penghargaan. Pembelajaran kooperatif mendorong siswa untuk bekerja sama dalam menyelesaikan tugas yang diberikan guru. Pembelajaran kooperatif bertujuan meningkatkan prestasi belajar akademik siswa, mengakaji keberagaman dan mengembangkan keterampilan sosial siswa. Student Teams Achievement Division (STAD) merupakan salah satu tipe pembelajaran kooperatif. Slavin (Jamdin, dkk, 2019: 84) mengatakan bahwa pembelajaran kooperatif tipe STAD menempatkan siswa pada kelompok belajar yang merupakan campuran berdasarkan tingkat kinerja, jenis kelamin dan suku, yang beranggotakan empat atau lima orang. Agar seluruh anggota kelompok dapat menguasai materi pelajaran, siswa melakukan kerja kelompok setelah guru menyajikan pelajaran. STAD terdiri dari lima komponen utama, yaitu presentasi kelas, kelompok, kuis (tes), skor peningkatan individual, dan penghargaan kelompok. Priansa (2017: 331) mengemukakan bahwa keunggulan model 
pembelajaran kooperatif tipe STAD adalah memberikan kesempatan kepada siswa untuk menggunakan ketrampilan bertanya dan membahas suatu masalah, serta lebih intensif dalam melakukan penyelidikan mengenai suatu masalah. Penggunaan pembelajaran kooperatif tipe STAD dapat membuat siswa lebih aktif terlibat dalam pembelajaran dan lebih aktif dalam diskusi sehingga siswa memperoleh pemahaman yang lebih besar.

\section{Metode Penelitian}

Metode penelitian yang digunakan adalah Quasi-Eksperiment dengan desain Nonequivalen Pretest-Posttest Control Group Design. Tabel 1 menyajikan desain penelitian.

Tabel 1. Desain Penelitian

\begin{tabular}{ccc}
\hline \multicolumn{1}{c}{ KAM } & \multicolumn{2}{c}{ Model Pembelajaran } \\
\hline (Level) & STAD & PL \\
\hline KAM Tinggi (KT) & KT-STAD & KT-PL \\
\hline KAM Sedang (KS) & KT-KS & KT-KS \\
\hline KAM Rendah (KR) & KT-KR & KT-KR \\
\hline
\end{tabular}

Siswa kelas VIII SMP Kristen Kalam Kudus Ambon yang terdiri dari dua kelas merupakan sampel dalam penelitian ini. Analisis data menggunakan statistik deskriptif dan statistik inferensial. Data penelitian kemampuan pemecahan masalah dan penalaran matematis dianalisis menggunakan independent T-test. Untuk mengukur peningkatan kemampuan pemecahan masalah dan penalaran matematis digunakan $N$ gain ternomalisasi.

\section{Hasil dan Pembahasan}

Penelitian ini menggunakan dua kelompok, yaitu kelompok eksperimen dan kelompok kontrol. Kedua kelompok tersebut diberikan tes untuk mengukur kemampuan awal mereka. Tujuan dilakukannya tes tersebut adalah mengidentifikasi dan mendistribusikan masing-masing siswa pada level tinggi, sedang dan rendah. Tabel 2 menyajikan KAM siswa perlevel.

Tabel 2. Distribusi KAM siswa pada berbagai level

\begin{tabular}{cccc}
\hline Level & \multicolumn{2}{c}{ Kelas } & \multirow{2}{*}{ Jumlah } \\
\cline { 2 - 3 } Kemampuan & Eksperimen & Kontrol & \\
\hline Tinggi & 6 & 6 & 12 \\
\hline Sedang & 9 & 11 & 20 \\
\hline Rendah & 5 & 3 & 8 \\
\hline Total Siswa & 20 & 20 & 40 \\
\hline
\end{tabular}

KAM siswa perlevel kemampuan seperti diperlihatkan pada tabel 2, menunjukkan bahwa kemampuan awal matematis siswa pada kelompok eksperimen dan kelompok kontrol memiliki frekuensi terbesar berada pada KAM level sedang, dengan jumlah total kelompok eksperimen dan kelompok kontrol sebanyak 20 siswa. Distribusi ini mengindikasikan bahwa secara rata-rata kemampuan awal matematis siswa termasuk dalam kategori sedang.

Untuk mengukur kemampuan pemecahan masalah dan penalaran matematis siswa dilakukan pretest dan posttest. Pretest diberikan sebelum siswa belajar dengan menggunakan model pembelajaran kooperatif tipe STAD dan pengajaran langsung. Posttest diberikan setelah siswa belajar dengan menggunakan model pembelajaran kooperatif tipe STAD dalam melihat peningkatan kemampuan pemecahan masalah dan penalaran matematis berdasarkan keseluruhan siswa maupun KAM (level tinggi, sedang dan rendah). Dengan menggunakan $N$-gain sebagai alat pengujian, diperoleh bahwa kelompok siswa yang mendapatkan pembelajaran dengan model kooperatif tipe STAD memperoleh peningkatan kemampuan pemecahan masalah dan penalaran matematis lebih tinggi dari kelompok yang menggunakan pengajaran langsung. Gambar 1 menyajikan hasil perbedaan peningkatan kemampuan pemecahan masalah matematis yang ditinjau dari KAM siswa.

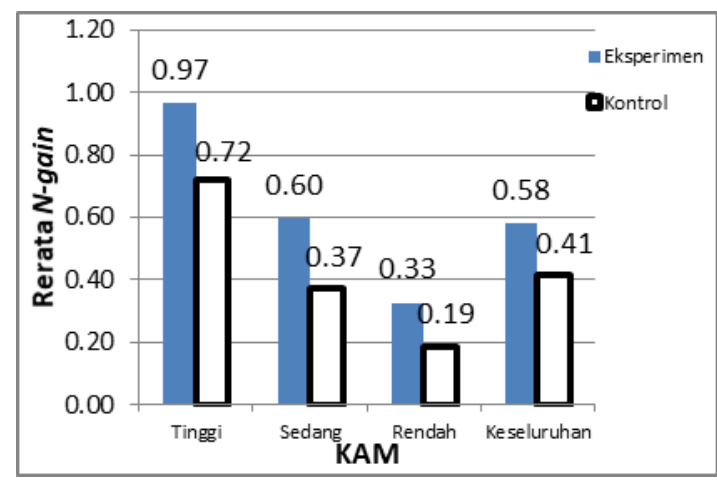

Gambar 1. Grafik rerata $N$-gain untuk berbagai level kemampuan pemecahan masalah matematis

Berdasarkan Gambar 1, dapat dilihat perbedaan peningkatan kemampuan pemecahan masalah antara siswa yang belajar dengan menggunakan model kooperatif tipe STAD dan pengajaran langsung. Perbedaan peningkatan ini menunjukkan bahwa model kooperatif tipe STAD memberikan kontribusi lebih baik dari model pengajaran langsung dalam meningkatkan kemampuan pemecahan masalah matematis siswa, baik KAM level tinggi, sedang, dan rendah serta keseluruhan siswa. Dapat dilihat bahwa siswa dengan kemampuan awal yag baik dapat terlibat aktif dalam kegiatan pembelajaran dan dapat menyelesaikan permasalah matematika yang dihadapi. 
$N$-gain digunakan sebagai tolak ukur kriteria peningkatan untuk melihat ada tidaknya perbedaan peningkatan kemampuan pemecahan masalah matematis siswa. Pertama yang harus dilakukan adalah melakukan uji normalitas dan homogenitas data. Dari hasil uji normalitas, kelompok eksperimen maupun kelompok kontrol berdistribusi normal. Sedangkan dari hasil uji homogenitas, kelompok eksperimen maupun kelompok kontrol memiliki varians yang berbeda atau tidak homogen. Hasil-hasil uji prasyarat ditunjukkan pada Tabel 3.

Tabel 3. Hasil uji normalitas dan homogenitas kemampuan pemecahan masalah

\begin{tabular}{|c|c|c|c|c|}
\hline \multirow{3}{*}{ Kelas } & \multicolumn{4}{|c|}{ Normalitas } \\
\hline & \multicolumn{3}{|c|}{ Kolmogorov-Smirnov } & \multirow{2}{*}{ Keputusan } \\
\hline & Statistik & Df & Sig. & \\
\hline Eksperimen & 0,193 & 20 & 0,050 & Normal \\
\hline Kontrol & 0,128 & 20 & 0,200 & Normal \\
\hline & \multicolumn{4}{|c|}{ Homogenitas } \\
\hline Levene Uji & df1 & df2 & Sig. & Keputusan \\
\hline 4,225 & 1 & 38 & 0,046 & $\begin{array}{c}\text { Tidak } \\
\text { Homogen }\end{array}$ \\
\hline
\end{tabular}

Tidak terpenuhinya asumsi homogenitas, maka digunakan statistik nonparametrik dengan jenis uji Mann-Whitney $U$. Dengan menguji Ngain untuk melihat ada tidaknya perbedaan peningkatan kemampuan pemecahan masalah matematis kelompok eksperimen dan kelompok kontrol dengan hipotesis penelitian siswa yang belajar dengan menggunakan model kooperatif tipe STAD memiliki peningkatan kemampuan pemecahan masalah matematis lebih baik dari siswa yang belajar dengan menggunakan model pengajaran langsung. Tabel 4 menyajikan hasil uji perbedaan peningkatan kemampuan pemecahan masalah matematis.

Tabel 4. Hasil uji perbedaan peningkatan kemampuan pemecahan masalah kelompok eksperimen dan control

\begin{tabular}{cccc}
\hline Statistik & $\begin{array}{c}\text { Post_Rep_ } \\
\text { EK }\end{array}$ & Keterangan & Keputusan \\
\cline { 1 - 2 } $\begin{array}{c}\text { Mann- } \\
\text { Whitney } U\end{array}$ & 122,000 & & \\
\cline { 1 - 2 }$Z$ & $-2,119$ & Ho ditolak & $\begin{array}{c}\text { Terdapat } \\
\text { perbedaan }\end{array}$ \\
\cline { 1 - 2 } $\begin{array}{c}\text { Asymp. } \\
\text { Sig. (2- } \\
\text { tailed) }\end{array}$ & 0,034 & & \\
\hline
\end{tabular}

Dengan menggunakan uji Mann-Whitney $U$ diperoleh nilai Sig. (2-tailed) $=0,034$ lebih kecil dari 0,05 sehingga menerima hipotesis. Artinya peningkatan kemampuan pemecahan masalah matematis siswa yang belajar dengan menggunakan model kooperatif tipe STAD lebih baik dari siswa yang belajar dengan model pengajaran langsung.
Gambar 2 menyajikan hasil perbedaan peningkatan kemampuan penalaran matematis yang ditinjau dari KAM siswa.

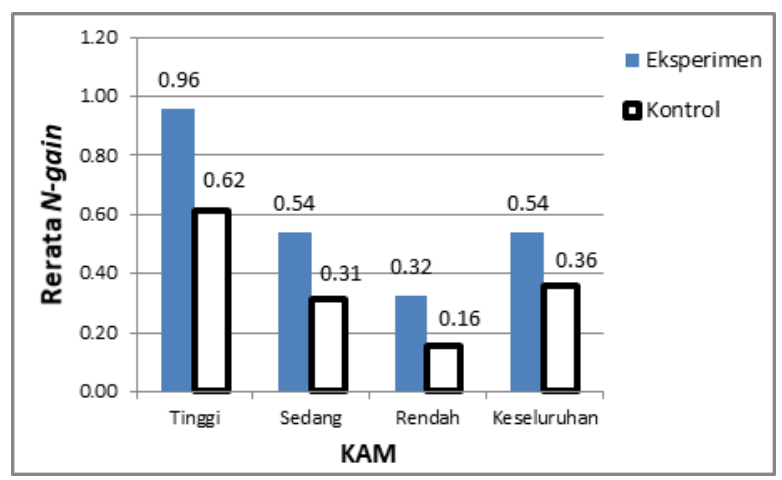

Gambar 2. Grafik rerata $\mathrm{N}$-gain untuk berbagai level kemampuan penalaran matematis

Perbedaan peningkatan kemampuan penalaran matematis seperti diperlihatkan pada Gambar 2 menunjukkan bahwa model kooperatif tipe STAD memberikan kontribusi lebih baik dari pengajaran langsung dalam upaya peningkatan kemampuan penalaran matematis siswa, baik KAM level tinggi, sedang, dan rendah serta keseluruhan siswa. Penggunaan $\mathrm{N}$-gain sebagai tolak ukur kriteria peningkatan dalam melihat perbedaan peningkatan kemampuan penalaran matematis siswa. Langkah awal yang harus dilakukan adalah melakukan uji normalitas dan homogenitas data. Dari hasil uji normalitas, kelompok eksperimen maupun kelompok kontrol berdistribusi tidak normal. Hasil-hasil uji prasyarat ditunjukkan pada Tabel 5.

Tabel 5. Hasil uji normalitas dan homogenitas kemampuan penalaran matematis

\begin{tabular}{ccccc}
\hline \multirow{2}{*}{ Kelas } & \multicolumn{4}{c}{ Normalitas } \\
\cline { 2 - 4 } & \multicolumn{3}{c}{ Kolmogorov-Smirnov } & Keputusan \\
\cline { 2 - 4 } Statistik & Df & Sig. & \\
\hline Eksperimen & 0,195 & 20 & 0,046 & $\begin{array}{c}\text { Tidak } \\
\text { Normal }\end{array}$ \\
\hline Kontrol & 0,221 & 20 & 0,021 & $\begin{array}{c}\text { Tidak } \\
\text { Normal }\end{array}$ \\
\hline
\end{tabular}

Karena data berdistribusi tidak normal, maka digunakan statistik nonparametrik dengan jenis uji Mann-Whitney $U$. Hipotesis penelitian adalah siswa yang belajar dengan menggunakan model kooperatif tipe STAD memiliki peningkatan kemampuan penalaran matematis lebih baik dari siswa yang belajar dengan menggunakan model pengajaran langsung. Hasil pengujian perbedaan peningkatan kemampuan penalaran matematis siswa dapat dilihat pada Tabel 6 .

Tabel 6. Hasil uji perbedaan peningkatan kemampuan penalaran matematis kelompok eksperimen dan kontrol

\begin{tabular}{|c|c|c|c|}
\hline $\mathbf{S}$ & $\begin{array}{c}\text { Post_Rep_ } \\
\text { EK }\end{array}$ & ngan & Kep \\
\hline
\end{tabular}




\begin{tabular}{cccc}
\hline $\begin{array}{c}\text { Mann- } \\
\text { Whitney } U\end{array}$ & 102,500 & & \\
\hline$Z$ & $-2,661$ & $\mathrm{H}_{0}$ ditolak & $\begin{array}{c}\text { Terdapat } \\
\text { perbedaan }\end{array}$ \\
\cline { 1 - 2 } $\begin{array}{c}\text { Asymp. } \\
\begin{array}{c}\text { Sig. (2- } \\
\text { tailed) }\end{array}\end{array}$ & 0,008 & & \\
\hline
\end{tabular}

Setelah melakukan pengujian dengan menggunakan uji Mann-Whitney $U$ diperoleh nilai Sig. $(2$-tailed $)=0,008$ lebih kecil dari 0,05 sehingga menerima hipotesis. Artinya siswa yang belajar dengan menggunakan model kooperatif tipe STAD memperoleh peningkatan kemampuan penalaran matematis lebih baik dari siswa yang belajar dengan menggunakan model pengajaran langsung.

\section{Kesimpulan}

Siswa yang belajar dengan menggunakan model kooperatif tipe STAD dan siswa yang belajar dengan menggunakan pengajaran langsung memiliki perbedaan peningkatan kemampuan pemecahan masalah. Siswa yang belajar dengan menggunakan model kooperatif tipe STAD dan siswa yang belajar dengan menggunakan pengajaran langsung memiliki perbedaan peningkatan kemampuan penalaran matematis. Berdasarkan KAM, siswa yang belajar dengan menggunakan model kooperatif tipe STAD dengan kemampuan awal tinggi, sedang, dan rendah memiliki peningkatan kemampuan pemecahan masalah dan penalaran matematis lebih baik dari siswa yang belajar dengan menggunakan pengajaran langsung.

\section{Daftar Pustaka}

Depdiknas. (2006). Peremendiknas Nomor 22 Tahun 2006 Tentang Standar Isi Sekolah Menengah Pertama. Jakarta: Depdiknas.

Hendriana Heris, dkk. (2017). Hard Skills dan Soft Skills Matematik Siswa. Bandung: Revika Aditama.

Jamdin, A., Ratumanan, T., \& Laamena, C. (2019). Pengembangan Perangkat Pembelajaran Berbasis Kooperatif Tipe STAD Pada Materi Perbandingan Untuk Siswa Kelas VII SMP IT Assalam Ambon. Jurnal Magister Pendidikan Matematika (JUMADIKA), 1(2), 81-90.

Muhsetyo, dkk. (2007). Pembelajaran Matematika SD. Jakarta: Universitas Terbuka.

Octizasari, G., \& Haji, S. (2018). Penerapan Model Pembelajaran RME Berbasis Ethnomatematika Untuk Meningkatkan Kemampuan Pemecahan Masalah Mahasiswa Calon Guru Pendidikan Matematika FKIP Universitas Bengkulu. Jurnal Pendidikan Matematika (Jupitek), 1(1), 1-7.

Priansa, D. J. (2017). Pengembangan Strategi dan Model Pembelajaran. Bandung: Pustaka Set 